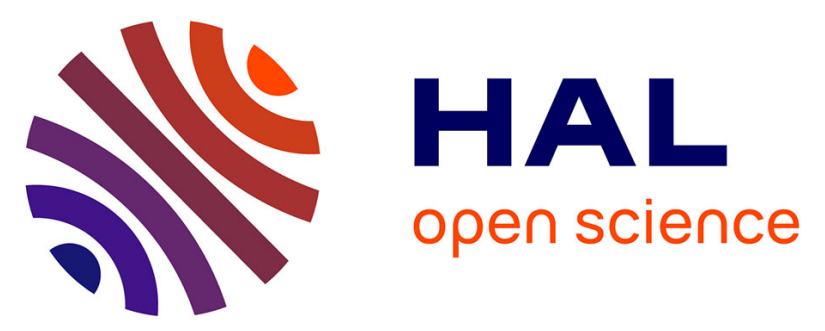

\title{
Heme Uptake in Lactobacillus sakei Evidenced by a New Energy Coupling Factor (ECF)-Like Transport System
} Emilie Verplaetse, Gwenaëlle André-Leroux, Philippe Duhutrel, Gwendoline Coeuret, Stéphane Chaillou, Christina Nielsen-Leroux, Marie-Christine Champomier-Vergès

\section{To cite this version:}

Emilie Verplaetse, Gwenaëlle André-Leroux, Philippe Duhutrel, Gwendoline Coeuret, Stéphane Chaillou, et al.. Heme Uptake in Lactobacillus sakei Evidenced by a New Energy Coupling Factor (ECF)-Like Transport System. Applied and Environmental Microbiology, 2020, 86 (18), pp.1-41. 10.1128/AEM.02847-19 . hal-02939244

\section{HAL Id: hal-02939244 \\ https://hal.inrae.fr/hal-02939244}

Submitted on 15 Sep 2020

HAL is a multi-disciplinary open access archive for the deposit and dissemination of scientific research documents, whether they are published or not. The documents may come from teaching and research institutions in France or abroad, or from public or private research centers.
L'archive ouverte pluridisciplinaire HAL, est destinée au dépôt et à la diffusion de documents scientifiques de niveau recherche, publiés ou non, émanant des établissements d'enseignement et de recherche français ou étrangers, des laboratoires publics ou privés. 
1 Title: Heme uptake in Lactobacillus sakei evidenced by a new ECF-like transport system.

2

3 Emilie Verplaetse ${ }^{1}$, Gwenaëlle André-Leroux ${ }^{2}$, Philippe Duhutrel ${ }^{1,3}$, Gwendoline Coeuret ${ }^{1}$,

4 Stéphane Chaillou ${ }^{1}$, Christina Nielsen-Leroux ${ }^{1}$, Marie-Christine Champomier-Vergès ${ }^{1 *}$

1) Université Paris-Saclay, INRAE, AgroParisTech, Micalis Institute, 78350, Jouy-en-

6 Josas, France.

2) Université Paris-Saclay, INRAE, MaIAGE, 78350, Jouy-en-Josas, France.

3) Present address: bioMérieux, 5 rue des Aqueducs, 69290 Craponne, France.

Running title: heme transport in Lactobacillus sakei

$15 *$ *Corresponding author: marie-christine.champomier-verges@inrae.fr

17 Key-words: iron, lactic acid bacteria, ABC-transporter 
19 Abstract

20 Lactobacillus sakei is a non-pathogenic lactic acid bacterium and a natural inhabitant of meat

21 ecosystems. Although red meat is a heme-rich environment, L. sakei does not need iron or

22 heme for growth, while possessing a heme-dependent catalase. Iron incorporation into L. sakei

23 from myoglobin and hemoglobin was formerly shown by microscopy and the L. sakei genome

24 reveals the complete equipment for iron and heme transport. Here, we report the

25 characterization of a five-gene cluster (lsa1836-1840) encoding a putative metal iron ABC

26 transporter. Interestingly, this cluster, together with a heme dependent catalase gene, is also

27 conserved in other species from the meat ecosystem. Our bioinformatic analyses revealed that

28 the locus might correspond to a complete machinery of an Energy Coupling Factor (ECF)

29 transport system. We quantified in vitro the intracellular heme in wild-type (WT) and in our

$30 \Delta l$ sal836-1840 deletion mutant using an intracellular heme sensor and ICP-Mass spectrometry

31 for quantifying incorporated ${ }^{57} \mathrm{Fe}$ heme. We showed that in the WT L. sakei, heme

32 accumulation occurs rapidly and massively in the presence of hemin, while the deletion mutant

33 was impaired in heme uptake; this ability was restored by in trans complementation. Our

34 results establish the main role of the L. sakei Lsa1836-1840 ECF-like system in heme uptake.

35 Therefore, this research outcome sheds new light on other possible functions of ECF-like

36 systems.

39 Importance

40 Lactobacillus sakei is a non-pathogenic bacterial species exhibiting high fitness in heme rich

41 environments such as meat products, although it does not need iron nor heme for growth.

42 Heme capture and utilization capacities are often associated with pathogenic species and are

43 considered as virulence-associated factors in the infected hosts. For these reasons, iron 
44 acquisition systems have been deeply studied in such species, while for non-pathogenic

45 bacteria the information is scarce. Genomic data revealed that several putative iron transporters

46 are present in the genome of the lactic acid bacterium L. sakei. In this study, we demonstrate

47 that one of them, is an ECF-like ABC transporter with a functional role in heme transport. Such

48 evidence has not yet been brought for an ECF, therefore our study reveals a new class of heme

49 transport system.

50

51 
52

53

54

55

56

57

58

59

60

61

62

63

64

\section{Introduction}

Iron is an essential element for almost all living organisms (1) and heme, an iron-containing porphyrin, is both a cofactor of key cellular enzymes and an iron source for bacteria. Many bacteria encode the complete heme biosynthesis pathway to be autonomous for heme production and partly to guarantee their iron supply. However, some others lack heme biosynthetic enzymes and rely on the environment to fulfill their heme requirements. Lactococcus lactis and all known Lactobacilli are heme-auxotrophic bacteria (2). Also, it is well established that lactic acid bacteria do not require iron to grow (3) and that their growth is unaffected by iron deprivation. Nevertheless, numerous lactic acid bacteria, such as L. lactis, Lactobacillus plantarum, or Enterococcus faecalis, require exogenous heme to activate respiration growth in the presence of heme (2).

Lactobacillus sakei is a non-pathogenic lactic acid bacterium frequently found on fresh meat. $L$. sakei is systematically associated with meat products and in particular with raw meat products stored at low temperature and under vacuum packaging (4). Interestingly, abundance of $L$. sakei has been shown to prevent growth of undesirable pathogens such as Listeria monocytogenes $(5,6)$, Escherichia coli $\mathrm{O} 157: \mathrm{H} 7$ in both cooked and minced meat $(5,7,8)$, and of spoilers such as Brochothrix thermosfacta $(7,8)$. Therefore, this species is often used as a bioprotective culture in meat products. Nevertheless, mechanisms of synergy and competition between species in such complex matrices are still poorly understood (9). Meat, can be considered as a growth medium naturally rich in iron and heme. Quantification of total iron content in raw meat reported a mean of $2.09 \mathrm{mg}$ total iron/100 $\mathrm{g}$ for four beef meat cuts in which $87 \%$ was heme iron (10). Although L. sakei has a tropism for meat and is known to possess a heme-dependent catalase (11), it is considered to be a bacterium that requires neither iron nor heme to grow (12). 
77 First insights on iron/heme utilization by $L$. sakei came from its whole genome analysis (13) with the identification of coding sequences of several iron transporters, regulators and ironcontaining enzymes. Later, microscopy analysis of $L$. sakei cells combined to spectroscopy methods showed that $L$. sakei is able to incorporate iron atoms from complexed iron such as myoglobin, hemoglobin, hematin, and transferrin (12). This suggested that L. sakei may display heme or heminic-iron storage ability, although the analytical method used was not quantitative and the precise amount of iron compound that $L$. sakei is able to store was not determined.

Hematin did not show any effect on growth of $L$. sakei, but hematin has been shown to prolong bacteria viability in stationary phase (13). However, the mechanisms underlining L. sakei survival in the presence of heme need to be unraveled.

Heme acquisition systems have mainly been studied in Gram-negative and Gram-positive pathogens that acquire heme from host hemoproteins in a two steps process (for a review, see (14-16)). First, cell surface or secreted proteins scavenge free heme molecules or complexed heme. Then, transmembrane transporters, generally ATP-binding cassette (ABC) transporters, carry the heme moiety into the intracellular space. Gram-positive bacteria rely mainly on surface-exposed receptors that shuttle heme through the cell-wall and deliver it to an $\mathrm{ABC}$ transporter for subsequent transfer into the cytoplasm. Within Gram-positive pathogens, one of the most well characterized heme uptake system is the Staphylococcus aureus Iron Surface Determinants (Isd) system. The staphylococcal machinery is inserted into a ten-gene locus encoding cell-wall anchored proteins (IsdABCH), a membrane transport system (IsdDEF), a sortase (SrtB) and two cytoplasmic heme-oxygenases (IsdG and IsdI) $(17,18)$. IsdB and IsdH are responsible for binding host hemoproteins or heme. IsdA extracts heme from IsdB or IsdH and transfers it to IsdC. Funneled heme is finally transferred into the cytoplasm through the membrane by the IsdDEF ABC transporter where it is finally degraded to release free iron by the heme oxygenases IsdG and IsdI. Several of these Isd proteins contain Near iron Transporter 
102

103

104

105

106

107

108

109

110

111

112

113

114

115

116

117

118

119

120

121

122

123

124

125

126

(NEAT) domain, present only in Gram-positive bacteria, and specific to interact with hemoproteins and heme. NEAT domain is a 150 -acid residues domain that despite sequence variability displays a conserved $\beta$-barrel and a hydrophobic pocket involved in heme binding (19).

Thus far, heme acquisition systems in heme auxotrophic organisms have only been reported for Streptococci $(15,20,21)$. In S. pyogenes, the system involves the Shr and Shp NEAT-domain proteins and the Hts $\mathrm{ABC}$ transporter (20, 22, 23). In Lactococcus lactis, heme homeostasis, especially heme efflux systems, have been deeply characterized $(24,25)$. Nevertheless, the acquisition of exogenous heme remains poorly characterized. Heme transport across $L$. sakei membrane is still unknown. Additionally, bioinformatic analysis shows that the genome of $L$. sakei does not contain any NEAT domain (13) which suggests that heme transit could involve transport systems distinct from Streptococci and S. aureus (14).

Regarding prokaryotic metal ion uptake transporters, comparative and functional genomic analysis have identified Energy-Coupling Factor (ECF) transporters as a novel type of ABC importers widespread in Gram-positive bacteria and first identified in lactic acid bacteria (26).

The studies identified genes encoding a ABC-ATPases plus three or four membrane proteins within the same or adjacent to operons, which were implicated in vitamin production or synthesis of metal-containing metalloenzymes (27). Their predicted role in cobalt or nickel ions uptake and delivery within the cell was demonstrated in Salmonella enterica and Rhodoccus capsulatus, respectively. Since then, ECF-coding genes have been evidenced in Mycoplasma, Ureaplasma and Streptococcus strains. They were also shown to function as importers not only for transition metal ions but also for vitamins as riboflavin and thiamine (27). Recently, several ECF systems have been characterized, among them folate and pantothenate ECF transport in Lactobacillus brevis, and cobalt ECF in $R$. capsulatus (28-31). It was evidenced that ECF transporters constitute a novel family of conserved membrane transporters in prokaryotes, 
127

128

129

130

131

132

133

134

135

136

137

138

139

140

141

142

143

144

145

146

147

148

149

150

151

while sharing a similar four domains organization as the ABC transporters. Each ECF displays a pair of cytosolic nucleotide-binding ATPases (the A and A' components also called EcfA and EcfA'), a membrane-embedded substrate-binding protein (the S component or the EcfS), and a transmembrane energy-coupling component (The T component or EcfT). The quadripartite organization has a 1:1:1:1 stoichiometry. Notably, the S component renders ECF mechanistically distinct from $\mathrm{ABC}$ transport systems as it is predicted to shuttle within the membrane, when carrying the bound substrate from the extracellular side into the cytosol (see the recent review (26)). Accordingly, the S-component solely confers substrate specificity to the uptake system (28). Till the 2000s, folate, riboflavin and thiamine ECF importers have been reported for L. lactis (32-34). Similarly, folate, hydroxyl pyrimidine and pantothenate ECFs have been reported and structurally characterized for L. brevis $(28,30,31)$, both Gram-positive rod shape species of lactic acid bacteria.

In this paper, we mainly targeted $L$. sakei locus lsa1836-1840 encoding a putative ABC transporter, and demonstrated its role as a heme uptake system, combining in silico bioinformatics analysis with in vitro functional analysis. We showed that this system encodes the complete machinery of an ECF-like importer, including the extracellular proteins that initiate heme scavenging. In parallel, we quantified the heme-and heminic iron storage properties of $L$. sakei, and compared WT L. sakei with the $\Delta l s a 1836-1840$ L. sakei deletion and overexpression mutants using an intracellular heme-reporter gene and mass-spectrometry quantification of iron-labelled heme. We were able to show in vitro that this five-gene locus plays an important role in active heme import.

\section{Results}

\section{Putative iron and heme transport systems in Lactobacillus sakei}


152

Accurate analysis of the genome of L. sakei $23 \mathrm{~K}$ (13), focused on heme/iron transport systems and heme utilization enzymes, previously led to the identification of six putative iron/heme transport systems and one heme-degrading enzyme (Table 1). First, two genes $l s a 0246$ and lsa1699 encoding proton motive permeases, which belong to the MntH family of manganese uptake, might be involved in iron or heme uptake. Notably, in L. lactis, a mntH mutant was impaired in $\mathrm{Fe}^{2+}$ transport (35).

Second, an operon, composed of the genes lsa1194-1195 coding for poorly defined membrane proteins of the $\mathrm{CCC} 1$ family, is putatively involved in iron transport. In yeast, $\mathrm{CCC} 1$ is involved in the manganese and iron ions transport from the cytosol to the vacuole for storage (36).

Third, two ABC systems homologous to the HrtAB and Pef heme-detoxification systems present in L. lactis and Streptococcus agalactiae $(24,37)$ were also identified in L. sakei genome. These systems are encoded by the $l s a 1366-1367$ and $l s a 0419-0420$ genes, respectively. The sequencing of the $l s a 0419-0420$ region has confirmed the presence of a frameshift and indicated that these genes are not expressed in L. sakei $23 \mathrm{~K}$ strain. The lsal3661367 gene products are homologous to the L. lactis Llmg_0625-0624 encoded proteins. The $L$. lactis genes code for the HrtB and HrtA proteins, respectively (24). An in silico analysis of Lsa1367 and HrtB indicated that these proteins share 33\% of sequence identity and, accordingly, the same fold, as assessed by TOPPRED analysis (38). Particularly, the cytoplasmic-exposed Y168 and Y231 amino-acid residues, shown as important for HrtB-heme interaction in L. lactis (25), are also present in Lsa1367, which suggests that these genes might be homologous to the L. lactis heme export system.

Last, two iron or heme uptake ABC-transporters were identified. Markedly, the operon lsa0399-0402 encodes a Fhu system, sharing homology with various orthologous genes and operons encoding complexed iron transport systems, and possibly homologous to the Listeria 
177

178

179

180

181

182

183

184

185

186

187

188

189

190

191

192

193

194

195

196

197

198

199

200

201

monocytogenes HupCGD system. Also, L. monocytogenes shows that HupCGD and Fhu are involved in heme and ferrioxamine uptake, respectively (39).

Then, the ABC system encoded within $l$ sal836-1840 genes was automatically annotated as involved in cobalamin transport, whilst it shows some levels of similarities with heme import systems described in Gram-positive bacteria (40-43). At first, we carried out a multiple alignment of all putative substrate-binding lipoproteins encoded in the L. sakei $23 \mathrm{~K}$ genome and noticed that Lsa1839 protein was closely related to Lsa0399 from the Fhu system (data not shown), suggesting a possible link to iron/heme transport. Furthermore, if heme transportation would represent a specific fitness for growth in meat, we wondered whether other meat-borne bacteria would contain a similar cluster in their genome. As shown in Figure 1, comparative genomic analysis revealed that the $l$ sal $836-1840$ genes cluster is present in several species known to harbor a tropism for meat. The most interesting observation is that species harboring the lsa1836-1840-like cluster also have in their genome a katA gene, encoding a heme dependent catalase, while the other species lacking the cluster, such as Leuconostoc and Lactococcus, were shown to be deprived of catalase-encoding gene. Although such co-occurrence could not constitute a proof of the role of the lsa1836-1840 cluster in heme transport, this analysis provided an additional argument consolidating this hypothesis.

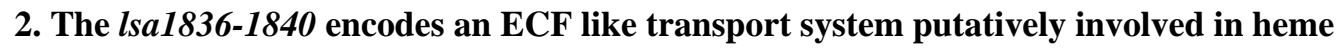
transport

Due to the conservation of the operon $l s a 1836-1840$, each of the five sequences was analyzed comprehensively using bioinformatics. It includes multiple sequence alignment, as well as 3D structure, proteins network and export peptide predictions. Lsa1836 shows a sequence similarity of more than $30 \%$, associated to a probability above $99 \%$ with an e-value of $8 . \mathrm{e}^{-15}$, to 
share structural homology with the membrane-embedded substrate-binding protein component

203 S from an ECF transporter of the closely related L. brevis, as computed by HHpred (44).

204 Accordingly, its sequence is predicted to be an integral membrane component with six

205 transmembrane helices, and a very high rate of hydrophobic and apolar residues, notably 11

206 tryptophan amino-acid residues among the 230 residues of the full-length protein (Fig. 2A).

207 HHpred analysis indicates that Lsa1837 shares more than $50 \%$ sequence similarity with the

208 ATPase subunits A and A' of the same ECF in L. brevis (Fig. 2A). With 100\% of probability

209 and a e-value of $1 . \mathrm{e}^{-35}$, Lsa1837 describes two repetitive domains, positioned at 9-247 and 299-

210531 , where each refers structurally to one ATPase very close in topology to the solved ATPase

211 subunits, A and A' of ECF from L. brevis, respectively. Appropriately, the N-terminal and C-

212 terminal ATPases, are predicted to contain an ATP-binding site. Lsa1837 could correspond to

213 the fusion of ATPase subunits, A and A'. Protein Lsa1838 shows sequence similarity of above

$21430 \%$, with a probability of $100 \%$ and e-value of $1 . \mathrm{e}^{-30}$, to share structural homology with the

215 membrane-embedded substrate-binding protein component T from the ECF transporter of $L$.

216 brevis (Fig. 2A). Interestingly, similar bioinformatic analysis of sequence and structure

217 prediction demonstrates that Lsa1839 and Lsa1840 share both $99.8 \%$ structural homology, and

218 e-value of $1 . \mathrm{e}^{-24}$ and of $1 . \mathrm{e}^{-21}$, with the $\beta$ and $\alpha$ domains of human transcobalamin, respectively

219 (Fig. 2A). Consistently, both proteins have an export signal located at their N-terminal end.

220 Taken together, these results predict with high confidence that the transcriptional unit encodes

221 the complete machinery of an ECF, including the extracellular proteins that initiate the

222 scavenging of iron-containing heme (Fig. 2A). Each protein compartment is predicted through

223 the presence/absence of its signal peptide as being extracellular, embedded in the membrane or

224 cytosolic. Correspondingly, every protein sequence associates appropriate subcellular location

225 with respect to its predicted function. In line with that, the network computed by String for the

226 set of proteins of the operon shows that they interact together from a central connection related 
227

228

229

230

231

232

234

235

236

237

238

239

240

241

242

243

244

245

246

247

248

249 No heme synthesis enzymes are present in L. sakei genome, nevertheless a gene coding for a

250 putative heme-degrading enzyme of the Dyp-type peroxidase family, $l s a 1831$, was identified in 251

to Lsa1837, which corresponds to the ATP-motor couple of ATPases (45). The transcriptional unit also encompasses Lsa1839 and Lsa1840, highly homologous to $\beta$ and $\alpha$ subunits of transcobalamin respectively, that are highly hypothesized to initiate the scavenging of heme from the extracellular medium. To address the capacity of those subunits of transcobalaminlike binding domain to bind a heme moiety, we homology-modeled Lsa1839 and Lsa1840. We then assembled the biological unit composed of the heterodimer formed by $\beta$ and $\alpha$ subunits, using the related 3D templates of corresponding subunit of haptocorrin and transcobalamin. Subsequently, an iron-containing heme moiety was docked into the groove, located at the interface of the complex formed by the two proteins. The docking highlights a heme-binding through polar and hydrophobic interactions. Nevertheless, no particular $\pi$ stacking could be detected (Fig. 2B). The redocking of cobalamin in haptocorrin and cyanocobalamin in transcobalamin shows a binding energy of -17 and $-12 \mathrm{kcal} / \mathrm{mol}$, respectively (Fig. $2 \mathrm{~B}$ ). With a binding energy of $-9 \mathrm{kcal} / \mathrm{mol}$, the heme bound to the crevice formed by Lsa1839 and Lsa1840 displays an affinity in the same range than the endogenous ligands, and emphasizes that the assembly composed of Lsa1839 and Lsa1840 could be compatible with the recognition and binding of a heme (Fig. 2B). To resume, Lsa1836-1840 describes a complete machinery that could be able to internalize a heme instead or additionally to a cobalamin molecule.

Importantly, this operon includes also the extracellular scavenging $\alpha$ - and $\beta$-like subunits of transcobalamin, which promotes the S-component Lsa1836 as likely very specific for ironcontaining heme. Markedly, the S-component displays a closely conserved fold, yet it does not show any of the strictly conserved residues known to bind specifically cobalt-containing cobalamin. the L. sakei genome (Table 1). Its structure is predicted to be close to DypB from Rhodococcus 
252

jostii (46). Interestingly, residues of DypB involved in the porphyrin-binding, namely Asp153, His226 and Asn246, are strictly conserved in Lsa1831 (47). Markedly, the lsa1831 gene is located upstream of the $l s a 1836-1840$ operon putatively involved in the active heme transport across the membrane.

Our bioinformatical analysis allows the functional reannotation of the lsa1836-1840 genes into the complete machinery of an Energy-Coupling Factor, possibly dedicated to the transport of iron through the heme (Fig. 3A-B). Consistently, the Lsa1831 enzyme, which is close to the lsa1836-1840 loci, could participate downstream to release iron from the heme once inside the cytoplasm.

\section{The Lsa1836-1840 is in vitro an effective actor of heme uptake in $L$. sakei.}

To confirm the above transporter as involved in heme trafficking across the membrane, a lsa1836-1840 deletion mutant was constructed by homologous recombination. The L. sakei Alsa1836-1840 mutant was analyzed for its capacity to internalize heme using an intracellular heme sensor developed by Lechardeur and co-workers (24). This molecular tool consists in a multicopy plasmid harboring a transcriptional fusion between the heme-inducible promoter of $h r t R$, the $h r t R$ coding sequence and the lacZ reporter gene, the pPhrt $h r t R$-lac (Table 2). In $L$. lactis, HrtR is a transcriptional regulator that represses the expression of a heme export system, HrtA and HrtB, as well as its own expression in the absence of heme. Upon heme binding, the repression is alleviated allowing the expression of the export proteins (24). As L. sakei possesses the lacLM genes, it was necessary to construct the $\Delta l s a 1836-1840$ mutant in the $L$. sakei RV2002 strain, a L. sakei 23K $\Delta l a c L M$ derivative, yielding the RV4057 strain (Table 2). The pPhrt hrtR-lac was then introduced in the RV2002 and RV4057 strains, yielding the RV2002 hrtR-lac and the RV4057 hrtR-lac strains (Table 2). $\beta$-Galactosidase ( $\beta$-Gal) activity of the RV4057 hrtR-lac strain, grown in a chemically defined medium (MCD) (48) in the 
277

278

279

280

281

282

283

284

285

286

287

288

289

290

291

292

293

294

295

296

297

298

299

300

presence of $0.5,1$ and $5 \mu \mathrm{M}$ hemin, was determined and compared to that of the RV2002 hrtRlac used as control (Fig. 4A). We showed that hemin reached the intracellular compartment as $\beta$-Gal expression was induced by hemin. Relative $\beta$-Gal activity of the RV4057 hrtR-lac mutant strain showed a slight increase as compared to the WT at $0.5 \mu \mathrm{M}$ heme but a statistically significant two-fold reduction was measured at $1 \mu \mathrm{M}$ heme and further, a $40 \%$ reduced activity was shown at higher hemin concentration. This indicates that the intracellular abundance of heme is significantly reduced in the RV4057 bacterial cells at 1 and $5 \mu \mathrm{M}$ heme, while it is similar to the WT at low heme concentrations. The method described above did not allow us to quantify the absolute amount of heme incorporated by bacteria as only cytosolic heme may interact with HrtR. Therefore, we used hemin labeled with the rare ${ }^{57}$ iron isotope $\left({ }^{57} \mathrm{Fe}-\mathrm{Hemin}\right)$ combined with Inductively Coupled Plasma Mass Spectrometry (ICP-MS) to measure with accuracy the total heminic-iron content of cells. Quantification of ${ }^{57} \mathrm{Fe}$ was used as a proxy to quantify heme. The absolute number of heme molecules incorporated by the $\Delta l s a 1836-1840$ mutant was also quantified using ${ }^{57} \mathrm{Fe}-$ hemin. The $\Delta l s a 1836-1840$ mutant was constructed in the WT L. sakei $23 \mathrm{~K}$ genetic background to obtain the RV4056 strain (Table 2). Bacteria were incubated in the MCD, in the absence or in the presence of 1,5 or $40 \mu \mathrm{M}$ of ${ }^{57} \mathrm{Fe}-$ hemin. ICP-MS quantification indicated that the ${ }^{57} \mathrm{Fe}$ content of the two strains was similar at 1 $\mu \mathrm{M}{ }^{57} \mathrm{Fe}$-hemin. By comparison with the WT, a 5-fold reduction in the ${ }^{57} \mathrm{Fe}$ content of the RV4056 strain at $5 \mu \mathrm{M}$ heme concentration and a 8-fold reduction at $40 \mu \mathrm{M}$ heme were measured (Fig. 4B).

To confirm the major role of the lsa1836-1840 gene products in heme acquisition, we analyzed the ${ }^{57} \mathrm{Fe}$ content of the RV4056 strain harboring the pPlsal836-1840, a multicopy plasmid that expresses the lsa1836-1840 operon under its own promoter, and compared it to the WT. The quantification of the ${ }^{57} \mathrm{Fe}$ atoms in the RV4056 pPlsa1836-1840 bacteria shows a 1.3 time and a 
3017 times higher iron content at 5 and $40 \mu \mathrm{M}{ }^{57} \mathrm{Fe}$-hemin, respectively, by comparison with

302 measurements done on WT bacteria (Fig. 4C).

303 These experiments confirm that the Lsa1836-1840 system is involved in vitro in the active

304 incorporation of heme in L. sakei.

305

306

4. Heme accumulates inside the L. sakei cytosol at low heme concentrations

307

We then addressed the ability for $L$. sakei to consume heme or iron to survive. We knew from a previous study that $L$. sakei incorporates preferentially heminic-compounds from the medium, probably as an adaptation to its meat environment (12). Data obtained previously showed that the incorporation of heme molecules are qualitatively correlated with both the concentration of heme in the growth medium, and the survival properties of the bacteria in stationary phase, suggesting that L. sakei could use heme or iron for its survival (See Supplemental text, Fig. S1

313 and S2). Nevertheless, heme incorporation could not be quantified with accuracy in the

314 previous studies. To tackle that, the intracellular heme levels incorporated by $L$. sakei were quantified. The RV2002 hrtR-lac strain (Table 2) was grown in MCD in the presence of increasing concentration of hemin, and the $\beta$-Gal activity of cells was measured (Fig. 5A). We showed that the $\beta$-Gal activity increased with the concentration of the hemin molecule in the

318 growth medium. A plateau was reached when cells were grown in $0.75-2.5 \mu \mathrm{M}$ hemin.

319 Incubation of cells in higher hemin concentrations did not allow to increase further $\beta$-Gal 320 activity.

\section{Heme incorporation in $L$. sakei is rapid and massive}

323 The absolute number of heme molecules incorporated by L. sakei $23 \mathrm{~K}$ was also quantified

324 using ${ }^{57} \mathrm{Fe}$-hemin (Fig. 5B). Cells were grown in MCD in the presence of labeled-hemin.

325 Measurements of the ${ }^{57} \mathrm{Fe}$ content of cells showed that the incorporation of ${ }^{57} \mathrm{Fe}-\mathrm{Hemin}$ is 
326

327

328

329

330

331

332

333

334

335

336

337

338

339

340

341

342

343

344

345

346

347

348

349

350

massive and rapid as bacteria are able to incorporate about $35,000{ }^{57} \mathrm{Fe}$ atoms of heminic origin, within 1 hour in the presence of $1 \mu \mathrm{M}{ }^{57} \mathrm{Fe}-\mathrm{Hemin}$ (Fig. 5B). The iron content of cells increased to 160,000 and 260,000 atoms in average when bacteria were grown in a medium containing 5 and $40 \mu \mathrm{M}$ of ${ }^{57} \mathrm{Fe}-\mathrm{Hemin}$, respectively. This indicates that the ${ }^{57} \mathrm{Fe}$ content of $L$. sakei cells increased with the ${ }^{57} \mathrm{Fe}-\mathrm{Hemin}$ concentration in the medium on the 1 to $40 \mu \mathrm{M}$ range. Measurements of the iron content of bacteria, growing in presence of ${ }^{57} \mathrm{Fe}-\mathrm{Hemin}$ for an extended period of time (19h), did not show additional ${ }^{57} \mathrm{Fe}$ accumulation in the bacteria (Fig. 5B). Instead, the number of ${ }^{57} \mathrm{Fe}$ atoms associated with bacteria decreased over time,

highlighting the fact that a massive incorporation of labeled-hemin occurs rapidly after bacteria being in contact with the molecules.

\section{Discussion}

Heme acquisition systems are poorly documented in lactic acid bacteria, probably because heme or iron are not mandatory for growth of these bacterial species, at least under non-aerobic conditions. However, acquisition of exogenous heme allows numerous lactic acid bacteria, among them L. lactis and Lactobacillus plantarum, to activate, if needed, a respiratory metabolism, when grown in the presence of oxygen $(2,49,50)$. This implies that heme has to cross the thick cell-wall of these Gram-positive organisms and may require heme transporters.

Thus far, heme acquisition systems in heme auxotrophic organisms have only been reported for Streptococci $(20,21)$ and S. pyogenes, where they both involve Shr and Shp NEAT-domain proteins and Hts $\mathrm{ABC}$ transporter $(20,22,23)$. To our knowledge, in lactic acid bacteria, NEAT domains have been identified in several species of lactic acid bacteria, including 15 Lactobacillus, 4 Leuconostoc and one Carnobacterium species (19) but no such functional heme transport has been identified so far and our present study confirmed that $L$. sakei proteins are devoid of such domains. 
351

352

353

354

355

356

357

358

359

360

361

362

363

364

365

366

367

368

369

370

371

372

373

374

375

In L. lactis, the $f h u C B G D R$ operon has been reported to be involved in heme uptake as a fhuD mutant is defective in respiration metabolism, suggesting a defect in heme import (15). A genome analysis of several lactic acid bacteria has revealed that a HupC/FepC heme uptake protein is present in L. lactis, L. plantarum, Lactobacillus brevis and L. sakei (15). This latter in L. sakei $23 \mathrm{~K}$ may correspond to locus $l s a 0399$ included in a fhu operon. An IsdE homolog has also been reported in L. brevis genome but the identity of this protein has not been experimentally verified (15).

The genome analysis of L. sakei $23 \mathrm{~K}$ (13), when focused on heme/iron transport systems and heme utilization enzymes, led to the identification of several putative iron transport systems, heme transport systems and heme-degrading enzymes. This heme uptake potential is completely consistent within the meat environment-adapted $L$. sakei. Similarly, the membrane transport system encoded by the 1 sal194-1195 genes, whose function is poorly defined, seems to be important for the bacterial physiology as a lsal194-1195 deletion affects the survival properties of this strain (see Supplemental text, Fig. S3 and Fig. S4).

Meanwhile, here, we report that the transcriptional unit lsa1836-1840 shows exquisite structure/function homology with the cobalamin ECF transporter, a new class of ATP-binding cassette importer recently identified in the internalization of cobalt and nickel ions (Fig. 2 and Fig. 3). Indeed, a comprehensive bioinformatics analysis indicates that the lsa1836-1840 locus codes for 5 proteins that assemble together to describe a complete importer machinery called Energy Coupling Factor. Any canonical ECF transporter comprises an energy-coupling module consisting of a transmembrane $\mathrm{T}$ protein (EcfT), two nucleotide-binding proteins (EcfA and EcfA'), and another transmembrane substrate-specific binding S protein (Ecsf). Indeed, Lsa1836-Lsa1838 shows high structural homology with Ecf-S, EcfA-A' and Ecf-T, respectively. Despite sharing similarities with $\mathrm{ABC}$-transporters, ECF transporters have different organizational and functional properties. The lack of soluble-binding proteins in ECF 
376

377

378

379

380

381

382

383

384

385

386

387

388

389

390

391

392

393

394

395

396

397

398

399

400

transporters differentiates them clearly from the canonical ABC-importers. Nevertheless here, $l s a 1839$ and $l$ sal 1840 code for proteins structurally close to $\beta$ and $\alpha$ subunits of transcobalaminbinding domain, respectively. They are highly suspected to be soluble proteins dedicated to scavenge heme from the extracellular compartment, and we hypothesize that they could bind it and then transfer it to Ecf-S component coded by lsa1836 (Fig. 3). In line with that, the heterodimer composed of Lsa1839 \& Lsa1840, possibly $\beta$ and $\alpha$ subunits, respectively, has been modeled in silico and was shown to accommodate, with high affinity, an iron-heme ligand at the binding site, located at the interface of the two proteins.

Internalization of the cobalt and nickel divalent cations through porphyrin moiety via this new class of importer has been demonstrated in lactic acid bacteria, such as L. lactis and L. brevis. However, nothing was known for the internalization/incorporation of iron-containing heme. A functional analysis of the $l s a 1836-1840$ gene products was undertaken using $\Delta l s a 1836-1840$ deletion mutant and a complemented strain. Our experiments indicate that the intracellular abundance of heme is significantly reduced in $\Delta l s a 1836-1840$ mutant bacterial cells at 1 and 5 $\mu \mathrm{M}$ heme, while it is similar to the WT at low heme concentrations. Reversely, the mutant strain, in which lsa1836-1840 is expressed from a multicopy plasmid, showed an increase in the heme uptake. Taken together, these experiments confirm that the Lsa1836-1840 system is involved in vitro in the active incorporation of heme in L. sakei. To our knowledge, this is the first time that an ECF is reported to being involved in heme incorporation. One could consider that such an ability to transport and accumulate heme/iron may represent an ecological fitness trait for surviving in the heme-rich meat ecosystem, where heme does not represent a limiting resource that would lead for competition strategies between species. This is probably true, not only for $L$. sakei but also for the other meat resident species as our synteny analysis for this operon shows that this feature could be shared within several Gram-positive meat-borne bacteria. 
401 Additionally, we were able to quantify the amount of heme internalized in the three genetic

402 contexts using isotope-labeled hemin and ICP-MS as well as to evaluate the intracellular

403 content of heme using the transcriptional fusion tool. We observed that the intracellular

404 abundance of heme increases with the concentration of heme in the growth medium and can be

405 detected with the intracellular sensor in the $0-2.5 \mu \mathrm{M}$ heme range (Fig. 5A). The drop in the $\beta$ -

406 gal activity at higher heme concentrations may result from regulation of heme/iron homeostasis

407 either through exportation of heme, degradation of the intracellular heme or storage of the

408 heme molecules, making them unable to interact with HrtR and promoting lac Z repression.

409 However, data obtained with the intracellular sensor at higher heme concentration $(5-40 \mu \mathrm{M})$

410 contrast with microscopic observations (Fig. S2) and ICP-MS measurements (Fig. 5B), that

411 reported a higher heminic-iron content in cells grown in $40 \mu \mathrm{M}$ heme than in $5 \mu \mathrm{M}$. Indeed, $\beta$ -

412 gal activity reflecting the abundance of intracellular heme was maximal when cells were grown

413 in a medium containing $1-2.5 \mu \mathrm{M}$ hemin (Fig. 5A), while ICP-MS measurements showed a 4.5

414 fold and 8 fold higher number of ${ }^{57} \mathrm{Fe}$ atoms in bacteria growing in $5 \mu \mathrm{M}$ or $40 \mu \mathrm{M}{ }^{57} \mathrm{Fe}-\mathrm{Hemin}$,

415 respectively, than in $1 \mu \mathrm{M}{ }^{57} \mathrm{Fe}-\mathrm{Hemin}$ (Fig. 4B). These data are in good agreement with EELS

416 analysis (Fig. S2), which strengthens the hypothesis that heme homeostasis occurs in L. sakei

417 and that the incorporated heme molecules would be degraded while iron is stored inside iron

418 storage proteins like Dps, of which orthologous genes exist in L. sakei. Thus, iron is detected in

419 L. sakei cells but not bound to heme and unable to interact with the intracellular heme sensor

420 HrtR. Storage of heme inside membrane proteins is still an open question as $L$. sakei does not

421 contain cytochromes nor menaquinones (12).

422 Further analysis is required not only to decipher the exact role of these proteins during the

423 different steps of heme transport across the $L$. sakei membrane and the fate of heme inside $L$.

424 sakei cells, but also to understand the molecular specificity of the Lsa1836-1840 machinery

425 towards iron-containing heme versus cobalamin. 


\section{Materials and methods}

428

429 Bacterial strains and general growth conditions.

430 The different bacterial strains used throughout this study are described in Table 1.

431 Lactobacillus sakei and its derivatives (RV2002 RV2002 hrtR-lac RV4056 RV4056c RV4057

432 RV4057 hrtR-lac) were propagated on MRS (2) at $30^{\circ} \mathrm{C}$. For physiological studies, the

433 chemically defined medium MCD (3) supplemented with $0.5 \%$ (wt/vol) glucose was used.

434 MCD contains no iron sources but contains possible traces of iron coming from various

435 components or distilled water. Incubation was performed at $30^{\circ} \mathrm{C}$ without stirring. Cell growth

436 and viability of cells in stationary phase were followed by measuring the optical density at 600

$437 \mathrm{~nm}\left(\mathrm{OD}_{600}\right)$ on a visible spectrophotometer (Secoman) and by the determination of the number

438 of $\mathrm{CFU} \mathrm{ml}{ }^{-1}$ after plating serial dilutions of samples on MRS agar. When needed, media were

439 supplemented with filtered hemin or hematin (Sigma-Aldrich) or with ${ }^{57} \mathrm{Fe}$-hemin (Frontier

440 Scientific) solutions resuspended in $50 \mathrm{mM} \mathrm{NaOH}$.

441 Escherichia coli $\mathrm{K}-12$ strain DH5 $\alpha$ was used as the host for plasmid construction and cloning

442 experiments. E. coli cells were chemically transformed as previously described (4). L. sakei

443 cells were transformed by electroporation as previously described (5). For routine growth, $E$.

444 coli strain was propagated in $\mathrm{LB}$ at $37^{\circ} \mathrm{C}$ under vigorous shaking $(175 \mathrm{rpm})$. The following

445 concentrations of antibiotic were used for bacterial selection: kanamycin at $20 \mu \mathrm{g} / \mathrm{mL}$ and

446 ampicillin at $100 \mu \mathrm{g} / \mathrm{mL}$ for $E$. coli and erythromycin at $5 \mu \mathrm{g} / \mathrm{mL}$ for $L$. sakei.

447

448 DNA manipulations.

449 Chromosomal DNA was extracted from Ls cells with DNA Isolation Kit for Cells and Tissues

450 (Roche, France). Plasmid DNA was extracted from E. coli by a standard alkaline lysis 
451

452

453

454

455

456

457

458

459

460

461

462

463

464

465

466

467

468

469

470

471

472

473

474

475

procedure with NucleoSpin ${ }^{\circledR}$ Plasmid Kit (Macherey Nagel, France). PCR-amplified fragments and digested fragments separated on $0.8 \%$ agarose gels were purified with kits from Qiagen (France). Restriction enzymes, Taq or Phusion high-fidelity polymerase (ThermoScientific, France) and T4 DNA ligase (Roche) were used in accordance with the manufacturer's recommendations. Oligonucleotides (Table 3) were synthesized by Eurogentec (Belgium). PCRs were performed in Applied Biosystems 2720 Thermak thermocycler (ABI). Nucleotide sequences of all constructs were determined by MWG - Eurofins (Germany).

\section{Bioinformatic analyses}

Analyses were performed in the sequenced L. sakei 23K genome (accession number: CR936503) as described in (13). Each fasta sequence of every gene of the operon comprised between $l$ sal 836 and $l s a 1840$ was retrieved from UnitProtKB server at http//www.uniprot.org/uniprot, uploaded then analyzed using HHpred server (44) that detects structural homologues. For Lsa1839 and Lsa1840, that partly shares strong structural homology with Geranyl-geranyltransferase type-I (pdb id 5nsa, chain A) (51), and $\beta$ domain of human haptocorrin (pdb id 4kki chain A) (52), intrinsic factor with cobalamin (pdb id 2pmv) (53) and transcobalamin (pdb id 2 bb6 chainA) (54) respectively, homology modeling was performed using Modeler, version Mod9v18 (55). The heterodimer was then formed with respect to the functional and structural assembly of $\alpha$ and $\beta$ domains of the native haptocorrin (52). Upon dimer formation, the best poses for heme inside the groove, which is located at the interface of this heterodimer, were computed using Autodock4 tool (56). The protocol and grid box were previously validated with the redocking of cyanocobalamin within human haptocorrin (4kki) (42) and of cobalamin within bovine transcobalamin (2bb6). To compute the binding energy of every complex, the parameters of the cobalt present in the cobalamin and cyanocobalamin were added to the parameter data table, whilst the iron parameters of the heme were already noted in 
476 the parameter data table. Then the docking poses were explored using the Lamarckian genetic

477 algorithm, and were subsequently analyzed with PyMOL of the Schrödinger suite (57).

478 Comparative genomic analysis for conservation of gene synteny between meat-borne bacteria

479 was carried out with the MicroScope Genome Annotation plateform, using the Genome

480 Synteny graphical output and the PkGDB Synteny Statistics (58)

481

482 Construction of plasmids and $L$. sakei mutant strains.

483 All the primers and plasmids used in this study are listed in Table 2 and 3. The $l$ sal $836-1840$

484 genes were inactivated by a 5118 bp deletion using double cross-over strategy. Upstream and

485 downstream fragments were obtained using primers pairs PHDU-lsa1836F/PHDU-lsa1836R

486 (731 bp) and PHDU-1sa1840F/PHDU-lsa1840R (742 bp) (Table 3). PCR fragments were joined

487 by SOE using primers PHDU-lsa1836F/PHDU-1sa1840R, and the resulting 1456 bp fragment

488 was cloned between EcoRI and KpnII sites in pRV300 yielding the pRV441 (Table 2). pRV441

489 was introduced in the L. sakei $23 \mathrm{~K}$ and the L. sakei $23 \mathrm{~K} \Delta$ lacLM (RV2002) strains by

490 electroporation as described previously (59). Selection was done on erythromycin sensitivity.

491 Second cross-over erythromycin sensitive candidates were screened using primers PHDU-

492 crblsa1840F and PHDU-crblsa1840R (Table 3). Deletion was then confirmed by sequencing

493 the concerned region and the lsa1836-1840 mutant strains were named RV4056 and RV4057

494 (Table 2).

495 To construct the RV2002 hrtR-lac and the RV4057 hrtR-lac strains, the pP $\mathrm{PrthrtR}_{\text {-lac }}$ (Table 2)

496 was transformed by electroporation into the corresponding mother strains.

497 For complementation, a pPlsa1836-1840 plasmid (Table 2) was constructed as follows: a DNA

498 fragment encompassing the promoter and the 5 genes of the lsal836-1840 operon was PCR

499 amplified, using the primers pair Lsa1836R/Lsa1840F (Table 3). The 5793 bp amplified

500 fragment was cloned into plasmid pRV566 at XmaI and NotI sites. The construct was verified 
501 by sequencing the whole DNA insert using the 566-F and 566-R primers (Table 3) as well as

502 internal primers. The pPlsa1836-1840 was introduced into RV4056 bacteria by electroporation

503 and transformed bacteria were selected for erythromycin resistance, yielding the RV4056c

504 complemented mutant strain.

505

$506 \beta$-galactosidase assay

507 Liquid cultures were usually grown in MCD into exponentially phase corresponding to a $A 600$

508 equal to $0,5-0.8$ and then incubated for $1 \mathrm{~h}$ at $30^{\circ} \mathrm{C}$ with hemin at the indicated concentration.

$509 \beta$-Galactosidase ( $\beta$-Gal) activity was assayed on bacteria permeabilized as described. $\beta$-Gal

510 activity was quantified by luminescence in an Infinite M200 spectroluminometer (Tecan), using

511 the $\beta$-Glo ${ }$ assay system as recommended by manufacturer (Promega).

512

513 Intracellular iron ${ }^{57} \mathbf{F e}$ determination

514 The various strains were grown in $\mathrm{MCD}$ to $A 600=0.5-0.7$ at $30^{\circ} \mathrm{C}$, prior to addition or not of

$5150.1,1,5$ or $40 \mu \mathrm{M}{ }^{57} \mathrm{Fe}$-labelled hemin (Frontier Scientific). Cells were then incubated at $30^{\circ} \mathrm{C}$

516 for an additional hour and overnight (19 hours). Cells were washed three times in $\mathrm{H}_{2} \mathrm{O}$

517 supplemented with $1 \mathrm{mM}$ EDTA. Cell pellets were desiccated and mineralized by successive

518 incubations in $65 \%$ nitric acid solution at $130{ }^{\circ} \mathrm{C} .{ }^{57} \mathrm{Fe}$ was quantified by Inductively Coupled

519 Plasma Mass Spectroscopy (ICP-MS) (Agilent 7700X), Géosciences, University of Montpellier

520 (France).

521

522 Statistical analysis

523 To determine if the differences in heme incorporation by L. sakei cells grown in the presence of

524 increasing concentrations of heme, measured using the molecular reporter, were different from

525 the control condition (cells grown in the absence of heme), the non-parametrical Kruskal- 
526 Wallis followed by the Dunn's multiple comparisons test with a family-wise significance and a

527 confidence level of 0.05 was performed using GraphPad Prism version 8.4.2 for macOS,

528 GraphPad Software, La Jolla California USA, www.graphpad.com.

529

530 Acknowledgments

531 This work, including Emilie Verplaetse post-doctoral grant, was funded from the French

532 National Research Agency ANR-11-IDEX-0003-02; ‘ALIAS' project.

533 The authors would like to thank Véronique Martin for her help in setting up the cobalt

534 parameter in the Autodock table parameter, Elise Abi-Khalil for the construction of the

535 pLsa1836-1840, Delphine Lechardeur and Alexandra Gruss for the heme reporter plasmid and

536 fruitful discussion and support.

537

538 
539

540 1. Neilands JB. 1981. Microbial Iron Compounds. Annu Rev Biochem 50:715-731.

541 2. Brooijmans R, Smit B, Santos F, van Riel J, de Vos WM, Hugenholtz J. 2009. Heme

542 and menaquinone induced electron transport in lactic acid bacteria. Microb Cell Factories 8:28.

543 3. Pandey A, Bringel F, Meyer J-M. 1994. Iron requirement and search for siderophores in

544 lactic acid bacteria. Appl Microbiol Biotechnol 40:735-739.

545 4. Zagorec M, Champomier-Vergès M-C. 2017. Lactobacillus sakei: A Starter for Sausage

546 Fermentation, a Protective Culture for Meat Products. Microorganisms 5:56.

547 5. Bredholt S, Nesbakken T, Holck A. 1999. Protective cultures inhibit growth of Listeria

548 monocytogenes and Escherichia coli $\mathrm{O} 157: \mathrm{H} 7$ in cooked, sliced, vacuum- and gas-packaged

549 meat. Int J Food Microbiol 53:43-52.

550 6. Leroy F, Lievens K, De Vuyst L. 2005. Modeling Bacteriocin Resistance and

551 Inactivation of Listeria innocua LMG 13568 by Lactobacillus sakei CTC 494 under Sausage

552 Fermentation Conditions. Appl Environ Microbiol 71:7567-7570.

$5537 . \quad$ Vermeiren L, Devlieghere F, Debevere J. 2004. Evaluation of meat born lactic acid

554 bacteria as protective cultures for the biopreservation of cooked meat products. Int J Food

555 Microbiol 96:149-164.

556 8. Chaillou S, Christieans S, Rivollier M, Lucquin I, Champomier-Vergès MC, Zagorec

557 M. 2014. Quantification and efficiency of Lactobacillus sakei strain mixtures used as protective

558 cultures in ground beef. Meat Sci 97:332-338.

559 9. Devlieghere F, Francois K, Vereecken KM, Geeraerd AH, Van Impe JF, Debevere J.

560 2004. Effect of chemicals on the microbial evolution in foods. J Food Prot 67:1977-1990.

561 10. Lombardi-Boccia G, Martinez-Dominguez B, Aguzzi A. 2002. Total Heme and Non-

562 heme Iron in Raw and Cooked Meats. J Food Sci 67:1738-1741.

563 11. Hertel C, Schmidt G, Fischer M, Oellers K, Hammes WP. 1998. Oxygen-Dependent 
564 Regulation of the Expression of the Catalase Gene katA of Lactobacillus sakei LTH677. Appl

565 Environ Microbiol 64:1359-1365.

566 12. Duhutrel P, Bordat C, Wu T-D, Zagorec M, Guerquin-Kern J-L, Champomier-Verges

567 M-C. 2010. Iron Sources Used by the Nonpathogenic Lactic Acid Bacterium Lactobacillus

568 sakei as Revealed by Electron Energy Loss Spectroscopy and Secondary-Ion Mass

569 Spectrometry. Appl Environ Microbiol 76:560-565.

570 13. Chaillou S, Champomier-Vergès M-C, Cornet M, Crutz-Le Coq A-M, Dudez A-M,

571 Martin V, Beaufils S, Darbon-Rongère E, Bossy R, Loux V, Zagorec M. 2005. The complete

572 genome sequence of the meat-borne lactic acid bacterium Lactobacillus sakei $23 \mathrm{~K}$. Nat

573 Biotechnol 23:1527-1533.

574 14. Huang W, Wilks A. 2017. Extracellular Heme Uptake and the Challenge of Bacterial

575 Cell Membranes. Annu Rev Biochem 86:799-823.

576 15. Gruss A, Borezée-Durant E, Lechardeur D. 2012. Chapter Three - Environmental Heme

577 Utilization by Heme-Auxotrophic Bacteria, p. 69-124. In Robert K. Poole (ed.), Advances in

578 Microbial Physiology. Academic Press.

579 16. Choby JE, Skaar EP. 2016. Heme Synthesis and Acquisition in Bacterial Pathogens. J

580 Mol Biol 428:3408-3428.

581 17. Anzaldi LL, Skaar EP. 2010. Overcoming the Heme Paradox: Heme Toxicity and

582 Tolerance in Bacterial Pathogens. Infect Immun 78:4977-4989.

583 18. Reniere ML, Torres VJ, Skaar EP. 2007. Intracellular metalloporphyrin metabolism in 584 Staphylococcus aureus. BioMetals 20:333-345.

585 19. Honsa ES, Maresso AW, Highlander SK. 2014. Molecular and Evolutionary Analysis of

586 NEAr-Iron Transporter (NEAT) Domains. PLoS ONE 9:e104794.

587 20. Bates CS, Montanez GE, Woods CR, Vincent RM, Eichenbaum Z. 2003. Identification

588 and Characterization of a Streptococcus pyogenes Operon Involved in Binding of 
589

590

591

592

593

594

595

596

597

598

599

600

601

602

603

604

605

606

607

608

609

610

611

612

613

Hemoproteins and Acquisition of Iron. Infect Immun 71:1042-1055.

21. Meehan M, Burke FM, Macken S, Owen P. 2010. Characterization of the haem-uptake

system of the equine pathogen Streptococcus equi subsp. equi. Microbiology 156:1824-1835.

22. Lei B, Smoot LM, Menning HM, Voyich JM, Kala SV, Deleo FR, Reid SD, Musser

JM. 2002. Identification and Characterization of a Novel Heme-Associated Cell Surface

Protein Made by Streptococcus pyogenes. Infect Immun 70:4494-4500.

23. Ouattara M, Bentley Cunha E, Li X, Huang Y-S, Dixon D, Eichenbaum Z. 2010. Shr of group A Streptococcus is a new type of composite NEAT protein involved in sequestering haem from methaemoglobin: Haem uptake and reduction by Shr. Mol Microbiol 78:739-756.

24. Lechardeur D, Cesselin B, Liebl U, Vos MH, Fernandez A, Brun C, Gruss A, Gaudu P. 2012. Discovery of Intracellular Heme-binding Protein HrtR, Which Controls Heme Efflux by the Conserved HrtB-HrtA Transporter in Lactococcus lactis. J Biol Chem 287:4752-4758.

25. Joubert L, Derré-Bobillot A, Gaudu P, Gruss A, Lechardeur D. 2014. HrtBA and menaquinones control haem homeostasis in Lactococcus lactis: Membrane and intracellular haem control in Lactococcus lactis. Mol Microbiol 93:823-833.

26. Rempel S, Stanek WK, Slotboom DJ. 2019. ECF-Type ATP-Binding Cassette Transporters. Annu Rev Biochem 88:551-576.

27. Finkenwirth F, Eitinger T. 2019. ECF-type ABC transporters for uptake of vitamins and transition metal ions into prokaryotic cells. Res Microbiol.

28. Wang T, Fu G, Pan X, Wu J, Gong X, Wang J, Shi Y. 2013. Structure of a bacterial energy-coupling factor transporter. Nature 497:272-276.

29. Bao Z, Qi X, Hong S, Xu K, He F, Zhang M, Chen J, Chao D, Zhao W, Li D, Wang J, Zhang P. 2017. Structure and mechanism of a group-I cobalt energy coupling factor transporter. Cell Res 27:675-687.

30. Zhang M, Bao Z, Zhao Q, Guo H, Xu K, Wang C, Zhang P. 2014. Structure of a 
614 pantothenate transporter and implications for ECF module sharing and energy coupling of 615 group II ECF transporters. Proc Natl Acad Sci U S A 111:18560-18565.

616 31. Xu K, Zhang M, Zhao Q, Yu F, Guo H, Wang C, He F, Ding J, Zhang P. 2013. Crystal

617 structure of a folate energy-coupling factor transporter from Lactobacillus brevis. Nature $618 \quad 497: 268-271$.

619 32. Rodionov DA, Hebbeln P, Eudes A, ter Beek J, Rodionova IA, Erkens GB, Slotboom 620 DJ, Gelfand MS, Osterman AL, Hanson AD, Eitinger T. 2009. A novel class of modular 621 transporters for vitamins in prokaryotes. J Bacteriol 191:42-51.

622 33. Henderson GB, Zevely EM, Huennekens FM. 1979. Mechanism of folate transport in 623 Lactobacillus casei: evidence for a component shared with the thiamine and biotin transport 624 systems. J Bacteriol 137:1308-1314.

625 34. Burgess CM, Slotboom DJ, Geertsma ER, Duurkens RH, Poolman B, van Sinderen D.

626 2006. The riboflavin transporter RibU in Lactococcus lactis: molecular characterization of gene 627 expression and the transport mechanism. J Bacteriol 188:2752-2760.

628 35. Turner MS, Tan YP, Giffard PM. 2007. Inactivation of an Iron Transporter in 629 Lactococcus lactis Results in Resistance to Tellurite and Oxidative Stress. Appl Environ 630 Microbiol 73:6144-6149.

631 36. Li L, Chen OS, Ward DM, Kaplan J. 2001. CCC1 Is a Transporter That Mediates 632 Vacuolar Iron Storage in Yeast. J Biol Chem 276:29515-29519.

633 37. Fernandez A, Lechardeur D, Derré-Bobillot A, Couvé E, Gaudu P, Gruss A. 2010. Two 634 Coregulated Efflux Transporters Modulate Intracellular Heme and Protoporphyrin IX 635 Availability in Streptococcus agalactiae. PLoS Pathog 6:e1000860.

636 38. von Heijne G. 1992. Membrane protein structure prediction. Hydrophobicity analysis 637 and the positive-inside rule. J Mol Biol 225:487-494.

638 39. Jin B, Newton SMC, Shao Y, Jiang X, Charbit A, Klebba PE. 2006. Iron acquisition 
639

640 Microbiol 59:1185-1198.

641 40. Abi-Khalil E, Segond D, Terpstra T, Andre-Leroux G, Kallassy M, Lereclus D, Bou-

642 Abdallah F, Nielsen-Leroux C. 2015. Heme interplay between IlsA and IsdC: Two structurally

643 different surface proteins from Bacillus cereus. Biochim Biophys Acta 1850:1930-1941.

644 41. Maresso AW, Chapa TJ, Schneewind O. 2006. Surface Protein IsdC and Sortase B Are

645 Required for Heme-Iron Scavenging of Bacillus anthracis. J Bacteriol 188:8145-8152.

646 42. Mazmanian SK, Skaar EP, Gaspar AH, Humayun M, Gornicki P, Jelenska J, Joachmiak

647 A, Missiakas DM, Schneewind O. 2003. Passage of heme-iron across the envelope of

648 Staphylococcus aureus. Science 299:906-909.

649 43. Mazmanian SK, Ton-That H, Su K, Schneewind O. 2002. An iron-regulated sortase

650 anchors a class of surface protein during Staphylococcus aureus pathogenesis. Proc Natl Acad

651 Sci 99:2293-2298.

652 44. Söding J, Biegert A, Lupas AN. 2005. The HHpred interactive server for protein

653 homology detection and structure prediction. Nucleic Acids Res 33:W244-248.

654 45. Szklarczyk D, Gable AL, Lyon D, Junge A, Wyder S, Huerta-Cepas J, Simonovic M,

655 Doncheva NT, Morris JH, Bork P, Jensen LJ, Mering C von. 2019. STRING v11: protein-

656 protein association networks with increased coverage, supporting functional discovery in

657 genome-wide experimental datasets. Nucleic Acids Res 47:D607-D613.

658 46. Roberts JN, Singh R, Grigg JC, Murphy MEP, Bugg TDH, Eltis LD. 2011.

659 Characterization of Dye-Decolorizing Peroxidases from Rhodococcus jostii RHA1.

660 Biochemistry 50:5108-5119.

661 47. Singh R, Grigg JC, Armstrong Z, Murphy MEP, Eltis LD. 2012. Distal Heme Pocket

662 Residues of B-type Dye-decolorizing Peroxidase: arginine but not aspartate is essential for

663 peroxidase activity. J Biol Chem 287:10623-10630. 
664 48. Lauret R, Morel-Deville F, Berthier F, Champomier-Verges M, Postma P, Ehrlich SD,

665 Zagorec M. 1996. Carbohydrate utilization in Lactobacillus sake. Appl Environ Microbiol $666 \quad 62: 1922-1927$.

667 49. Gaudu P, Vido K, Cesselin B, Kulakauskas S, Tremblay J, Rezaiki L, Lamberret G, 668 Sourice S, Duwat P, Gruss A. 2002. Respiration capacity and consequences in Lactococcus 669 lactis. Antonie Van Leeuwenhoek 82:263-269.

670 50. Lechardeur D, Cesselin B, Fernandez A, Lamberet G, Garrigues C, Pedersen M, Gaudu 671 P, Gruss A. 2011. Using heme as an energy boost for lactic acid bacteria. Curr Opin Biotechnol $672 \quad 22: 143-149$.

673 51. Bloch JS, Ruetz M, Kräutler B, Locher KP. 2017. Structure of the human

674 transcobalamin beta domain in four distinct states. PLOS ONE 12:e0184932.

675 52. Furger E, Frei DC, Schibli R, Fischer E, Prota AE. 2013. Structural Basis for Universal 676 Corrinoid Recognition by the Cobalamin Transport Protein Haptocorrin. J Biol Chem $677 \quad 288: 25466-25476$.

678 53. Mathews FS, Gordon MM, Chen Z, Rajashankar KR, Ealick SE, Alpers DH, Sukumar 679 N. 2007. Crystal structure of human intrinsic factor: Cobalamin complex at 2.6-A resolution. 680 Proc Natl Acad Sci 104:17311-17316.

681 54. Wuerges J, Garau G, Geremia S, Fedosov SN, Petersen TE, Randaccio L. 2006.

682 Structural basis for mammalian vitamin B12 transport by transcobalamin. Proc Natl Acad Sci $683 \quad 103: 4386-4391$.

684 55. Webb B, Sali A. 2016. Comparative Protein Structure Modeling Using MODELLER. 685 Curr Protoc Bioinforma 54:5.6.1-5.6.37.

686 56. Morris GM, Goodsell DS, Halliday RS, Huey R, Hart WE, Belew RK, Olson AJ. 1998.

687 Automated docking using a Lamarckian genetic algorithm and an empirical binding free energy 688 function. J Comput Chem 19:1639-1662. 
689

690

691

692

693

694

695

696

697

698

699

700

701

702

703

704

705

706

707

708

709

710

711

57. The PyMOL Molecular Graphics System, Version 2.0. Schrödinger, LLC.

58. Vallenet D, Belda E, Calteau A, Cruveiller S, Engelen S, Lajus A, Le Fèvre F, Longin

C, Mornico D, Roche D, Rouy Z, Salvignol G, Scarpelli C, Thil Smith AA, Weiman M,

Médigue C. 2013. MicroScope - an integrated microbial resource for the curation and

comparative analysis of genomic and metabolic data. Nucleic Acids Res 41:D636-D647.

59. Berthier F, Zagorec M, Champomier-Verges M, Ehrlich SD, Morel-Deville F. 1996.

Efficient transformation of Lactobacillus sake by electroporation. Microbiology 142:12731279.

60. Stentz R, Loizel C, Malleret C, Zagorec M. 2000. Development of Genetic Tools for Lactobacillus sakei: Disruption of the $\beta$-Galactosidase Gene and Use of lacZ as a Reporter Gene To Study Regulation of the Putative Copper ATPase, AtkB. Appl Environ Microbiol $66: 4272-4278$.

61. Leloup L, Ehrlich SD, Zagorec M, Morel-Deville F. 1997. Single-crossover integration in the Lactobacillus sake chromosome and insertional inactivation of the ptsI and lacL genes. Appl Environ Microbiol 63:2117-2123.

62. Alpert C-A, Crutz-Le Coq A-M, Malleret C, Zagorec M. 2003. Characterization of a Theta-Type Plasmid from Lactobacillus sakei: a Potential Basis for Low-Copy-Number Vectors in Lactobacilli. Appl Environ Microbiol 69:5574-5584. 
712 Table 1: Genes putatively involved in iron/heme transport and heme modification

\begin{tabular}{lll}
\hline $\begin{array}{l}\text { Locus tag and } \\
\text { Functional category }\end{array}$ & Protein ID & Predicted protein function \\
\hline & Genes putatively involved in iron/heme transport \\
\hline ABC transporters & & \\
Isa0399-0402 & CAI54700-CAI54703 & Fhu \\
Isa1836-1840 & CAI56143-CAI56147 & Putative metal ion ABC transporter, \\
& & cobalamin transporter \\
Isa1366-1367 & CAI55670-CAI55671 & Putative ABC exporter (heme-efflux \\
& & machinery)
\end{tabular}

Proton-motive force transporters

Isa0246

CAI54546

$\mathrm{Mn}^{2+} / \mathrm{Zn}^{2+} / \mathrm{Fe}^{2+}$ transporter

Isa1699

CAI56006

$\mathrm{Mn}^{2+} / \mathrm{Zn}^{2+} / \mathrm{Fe}^{2+}$ transporter

Membrane proteins

Isa1194-1195

CAI55498-CAI55499 Uncharacterized proteins

Gene putatively involved in heme modification

Isa1831

CAI56138

Dyp-type peroxidase

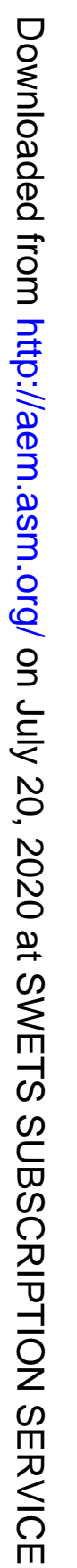

713

714 
715 Table 2: Strains and plasmids used in this study

716

\begin{tabular}{|c|c|c|}
\hline Strains or plasmids & Characteristics & References \\
\hline \multicolumn{3}{|l|}{ Strains } \\
\hline Lactobacillus sakei $23 \mathrm{~K}$ & sequenced strain & (13) \\
\hline RV2002 & $23 \mathrm{~K}$ derivative, $\Delta / a c L M$ & $(60)$ \\
\hline RV2002 hrtR-lac & $\mathrm{RV} 2002$ carrying the $\mathrm{pP}$ hrt $h r t R$-lac, ery ${ }^{\mathrm{R}}$ & This study \\
\hline RV4056 & $23 \mathrm{~K}$ derivative, $\Delta /$ sa1836-1840 & This study \\
\hline RV4056c & RV4056 carrying the pPlsa1836-1840, ery ${ }^{R}$ & This study \\
\hline RV4057 & RV2002 $\Delta / s a 1836-1840$ & This study \\
\hline RV4057 hrtR-lac & RV4057 carrying the $\mathrm{pP}_{\text {hrt }}$ hrtR-lac, ery ${ }^{\mathrm{R}}$ & This study \\
\hline \multicolumn{3}{|l|}{ Plasmids } \\
\hline pP hrt hrtR-lac & Plasmid carrying the $\mathrm{P}_{\text {hrtR }} h r t R$-lac transcriptional fusion & (24) \\
\hline pRV300 & $\begin{array}{l}\text { Shuttle vector, non-replicative in Lactobacillus; } \mathrm{Amp}^{\mathrm{R}} \text {, } \\
\mathrm{Erm}^{\mathrm{R}}\end{array}$ & (61) \\
\hline pRV566 & vector used for complementation; $\mathrm{Amp}^{\mathrm{R}}, \mathrm{Erm}^{\mathrm{R}}$ & (62) \\
\hline pRV441 & pRV300 derivative, exchange cassette for Isa1836-1840 & This study \\
\hline pPIsa1836-1840 & $\begin{array}{l}\text { pRV566 carrying the promoter and the Isa1836-1840 } \\
\text { coding sequences }\end{array}$ & This study \\
\hline
\end{tabular}

717

718

719

720

721

722 
723 Table 3: Oligonucleotides used in this study

\begin{tabular}{lll}
\hline Primer & Sequence $^{\mathbf{a}}$ (5'-3') & Restriction site \\
\hline PHDU-Isa1836F & CATGGTACCGGTCGGCTCAATTATGAGT & Kpnl \\
PHDU-Isa1836R & AATGAACTAGTTAGCGCTCGCAGCCTATATTGCGAGT & \\
PHDU-Isa1840F & AGCGCTAACTAGTTCATTAGACTTCCGTCACTTGTGAA & \\
PHDU-Isa1840R & CTGGAATTCATGCTGAGCGATGGTTTCT & EcoRl \\
PHDU-crblsa1840F & CGACAAGTCAACTCAGTGCTA & \\
PHDU-crblsa1840R & GTGAACCGTAATCTTGAGTG & \\
Lsa1836R & TTCCCGGGAACTTACAAAAGGCCACGC & Xmal \\
Lsa1840F & AAAAGCGGCCGCGCCTCCTTATAAAAACTG & Notl \\
$\mathbf{5 6 6 - F}$ & GCGAAAGAATGATGTGTTGG & \\
$\mathbf{5 6 6 - R}$ & CACACAGGAAACAGCTATGAC & \\
\hline
\end{tabular}

724

${ }^{a}$ underlined sequences indicate the location of restriction sites, and italicized letters indicate

726 complementary overlapping sequences used to join PCR fragments as described in the

727 materials and methods section.

728 
729

730

731

732

733

734

735

736

737

738

739

740

741

742

743

744

745

746

747

748

749

750

751

752

753

\section{Legends}

Figure 1: Gene synteny within and around the lsal836-1840 gene cluster of L. sakei $23 \mathrm{~K}$ with other Gram-positive species found frequently on meat products. Genes in grey background are unrelated to this cluster and are not conserved between the different genomes. The name of the species and of the strains used for analysis are depicted on the right. All of these species contain a katA gene (encoding a heme-dependent catalase) in their genome. Other meat-borne species including Leuconostoc, Lactococcus, Vagococcus species also found on meat are not shown due to the lack of both katA gene and lsa1836-1840 gene cluster.

Figure 2: Panel A details the structural and functional bioinformatic assessment for each gene of the lsa1836-1840 operon. Panel B focuses on Lsa1839 and Lsa1840 and highlights (left) the binding interaction and affinity of the human haptocorrin with cyano-cobalamin and bovine transcobalamin with cobalamin, respectively. They were used as 3D template and positive control for the modeling of transcobalamin-like proteins Lsa1840 and Lsa1839. Panel B (right) shows the best pose of iron containing heme as computed by Autodock 4 within the binding pocket formed at the interface of a and b subunits of homology modeled Lsa1840 and Lsa1839, respectively. The polar and hydrophobic interactions between the heme and $\alpha$ plus $\beta$ chains are highlighted as brown sticks.

Figure 3: A, Functional reannotation of the operon lsa1836-1840 from L. sakei $23 \mathrm{~K}$ after serial analysis of 3D structure/function prediction for each gene of the operon. B, Reconstitution of iron-containing heme transport, initially scavenged between the a and $b$ subunits of the transcobalamine-like transporter, coded by lsa1839-1840, then cargoed from the extracellular into the intracellular compartments through the complete ECF machinery coded by lsal836- 
754

755

756

757

758

759

760

761

762

763

764

765

766

767

768

769

770

771

772

773

774

775

776

777

778

1838 portion of the operon. Possibly, gene $l s a 1831$ positioned in the vicinity of the loci lsa1836-1840 could code for a protein Dyp-type peroxidase that ultimately releases the iron from the heme.

Figure 4: Heme incorporation is reduced in the $\Delta l s a 1836-1840$ L. sakei deletion mutant. A, In vivo detection of intracellular heme content of the RV2002 and $\Delta l$ sa1836-1840 (RV4057) mutant strains. Strains carrying the $\mathrm{pP}$ hrtRhrtR-lac were grown in hemin and $\beta$-Gal activity was quantified by luminescence (see "Materials and methods"). For each experiment, values of luminescence obtained with no added hemin are subtracted and $\beta$-Gal activity of strains was expressed as the percentage to the RV2002 strain for each hemin concentration. Mean values are shown $(n=3)$. Error bars represent the standard deviation. B, Quantification of the ${ }^{57} \mathrm{Fe}$ content of the WT (23K) and the $\Delta l s a 1836-1840$ (RV4056) strains grown in the absence and presence of indicated ${ }^{57} \mathrm{Fe}$-hemin concentrations. Results represent the mean and range from at least two independent experiments. C, Quantification of the ${ }^{57} \mathrm{Fe}$ content of the WT (23K), the $\Delta l s a 1836-1840$ (RV4056) and the $\Delta l s a 1836-1840$ pPlsa1836-1840 (RV4056c) strains grown in the absence and presence of indicated ${ }^{57} \mathrm{Fe}$-hemin concentrations. Results represent the mean and range of two independent experiments.

Figure 5: Quantification of heme incorporation in L. sakei. A, In vivo detection of intracellular hemin molecules through the expression of the lacZ gene. The L. sakei RV2002 hrtR-lac strain was grown for $1 \mathrm{~h}$ in the presence of the indicated concentrations of hemin. $\beta$-Gal activity was quantified by luminescence (see "Materials and methods"). Mean values are shown ( $\mathrm{n}=7)$.

Error bars represent the standard deviation. Conditions for which the $\beta$-Gal activity of cells is different as compared to the control condition $(0 \mu \mathrm{M}$ Hemin) are indicated with stars.

Significance is based on Kruskal- Wallis followed by the Dunn's multiple comparisons test 
779 with a $\mathrm{P}<0.05^{*}, \mathrm{P}<0.01^{* *}, \mathrm{P}<0.001^{* * *}$. B, Quantification of the ${ }^{57} \mathrm{Fe}$ content of the WT $(23 \mathrm{~K})$

780 strain grown in the absence and presence of ${ }^{57} \mathrm{Fe}$-hemin for $1 \mathrm{~h}$ and $19 \mathrm{~h}$. The mean values and

781 range of two independent experiments are shown. RLU, relative light units. 


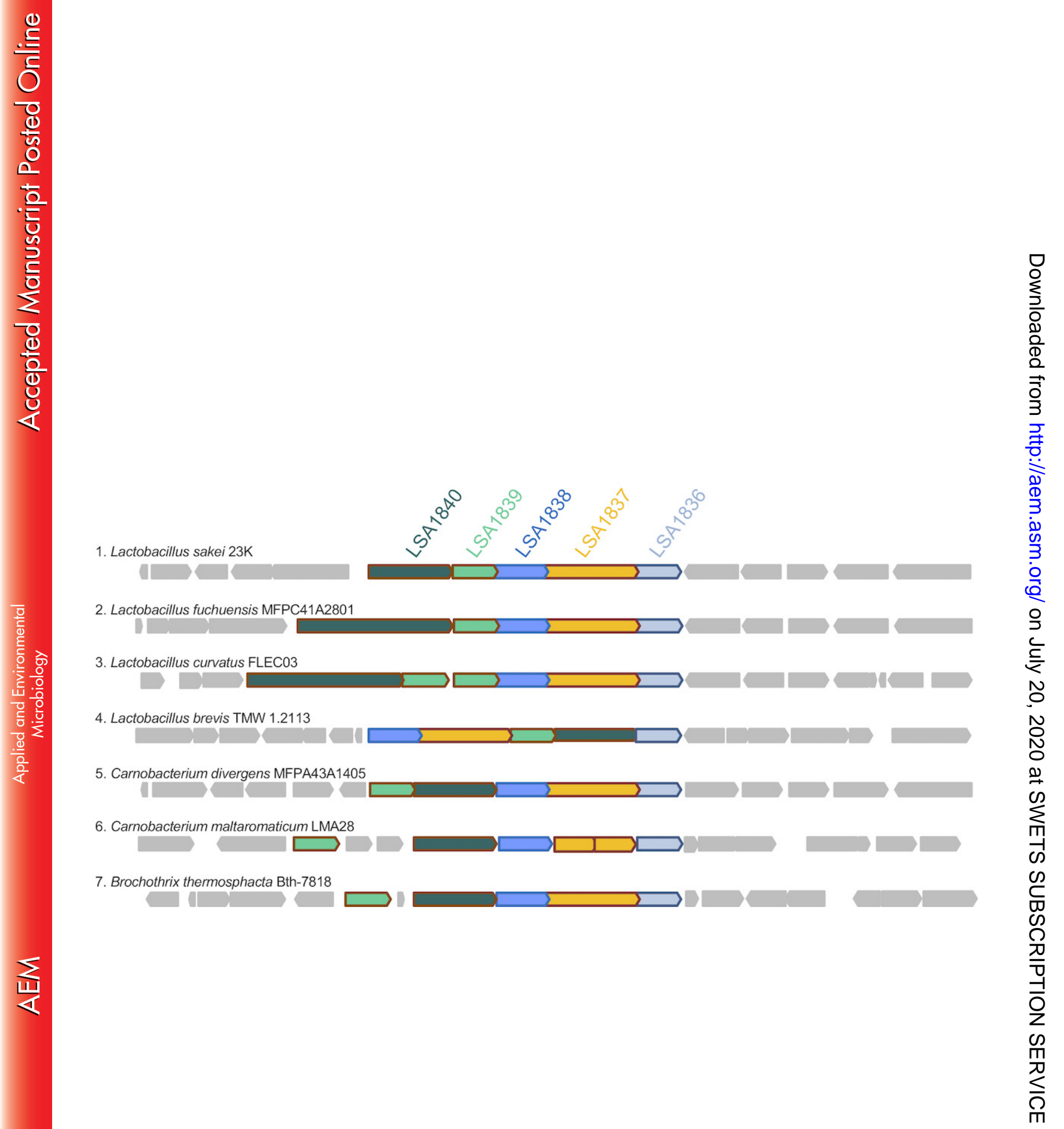


Lsa1840 transcobalamine $\alpha$ subunit

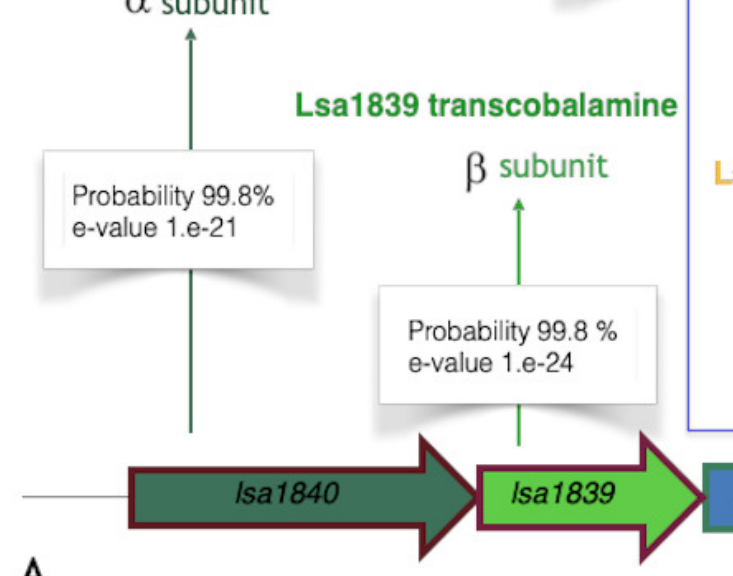

A
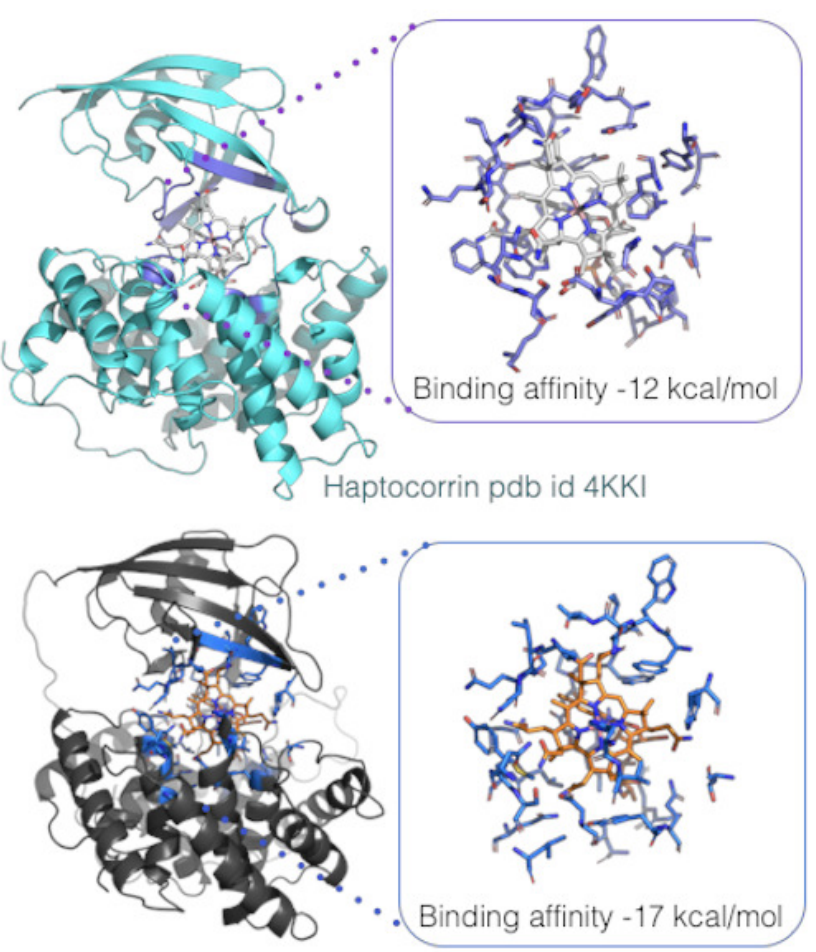

B
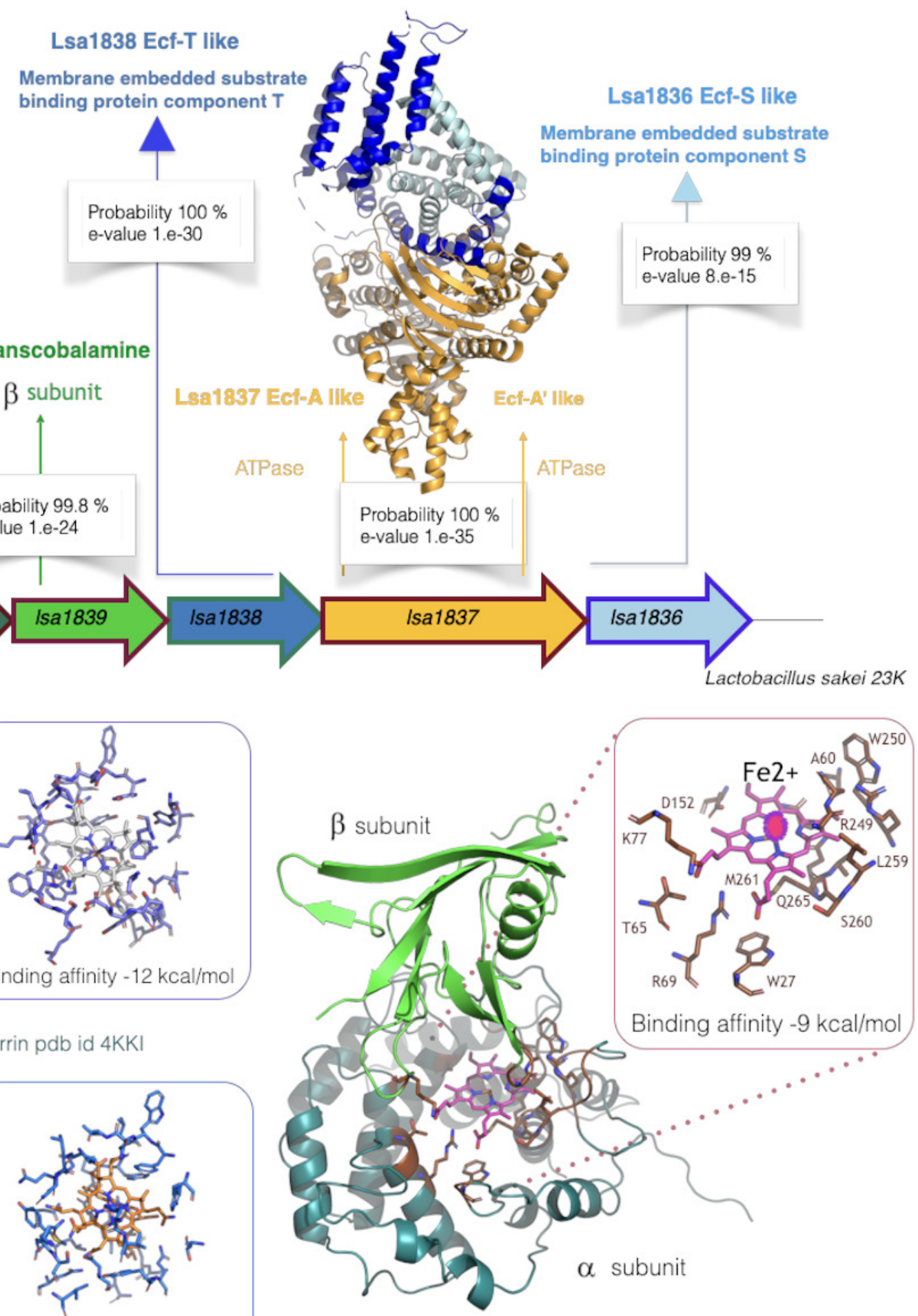

Homology model of Lsa 1839 and Lsa1840 


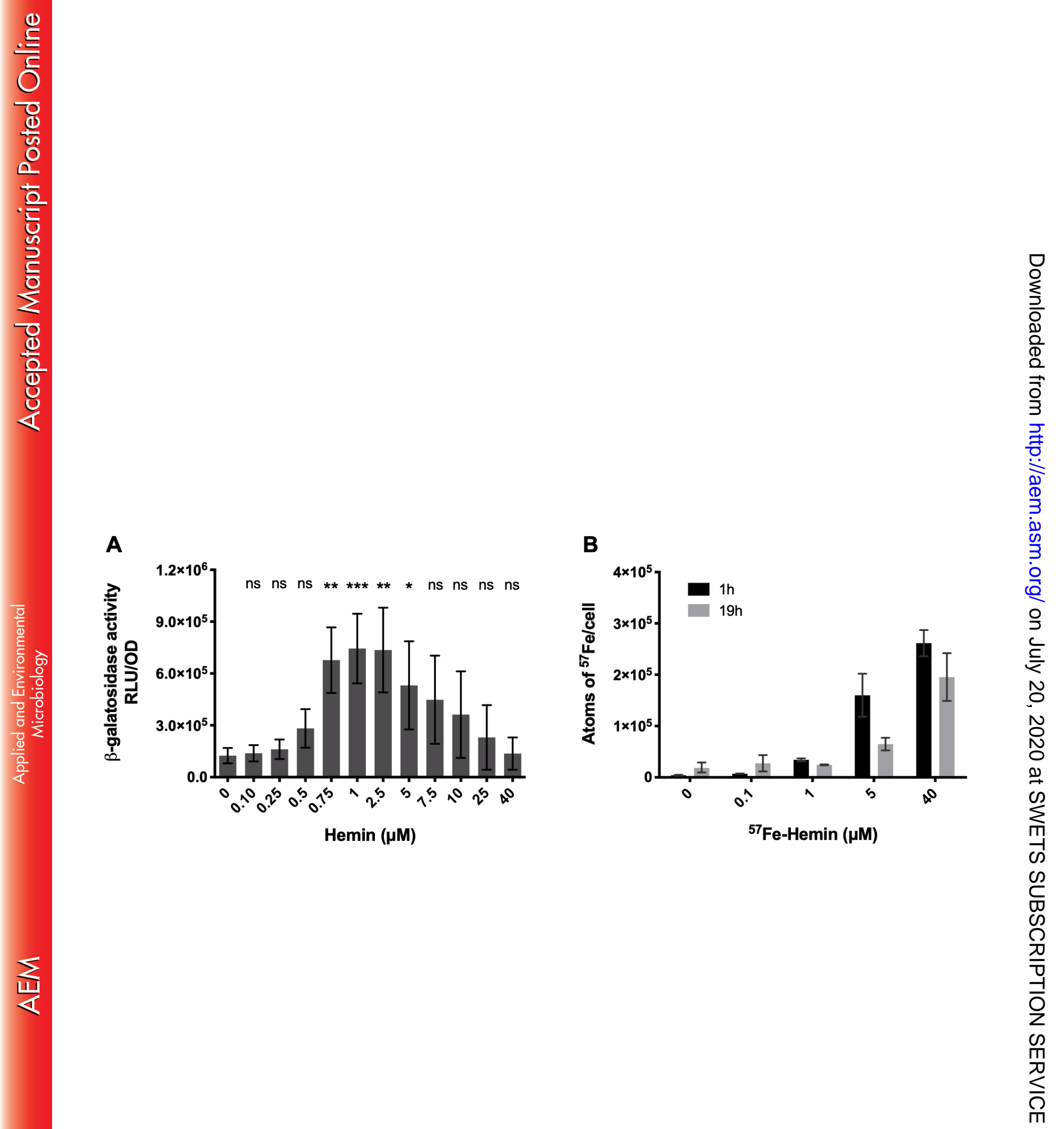




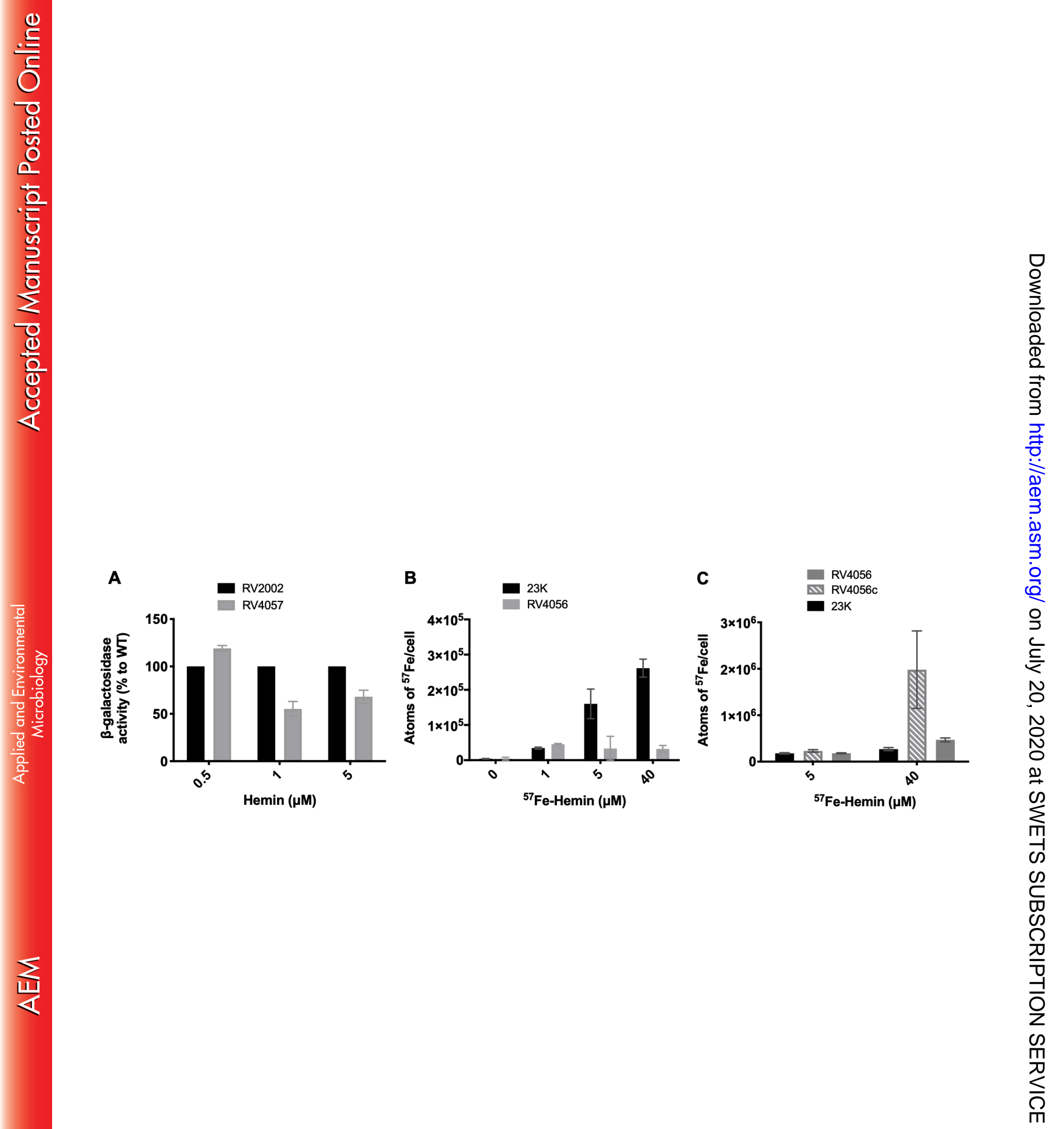




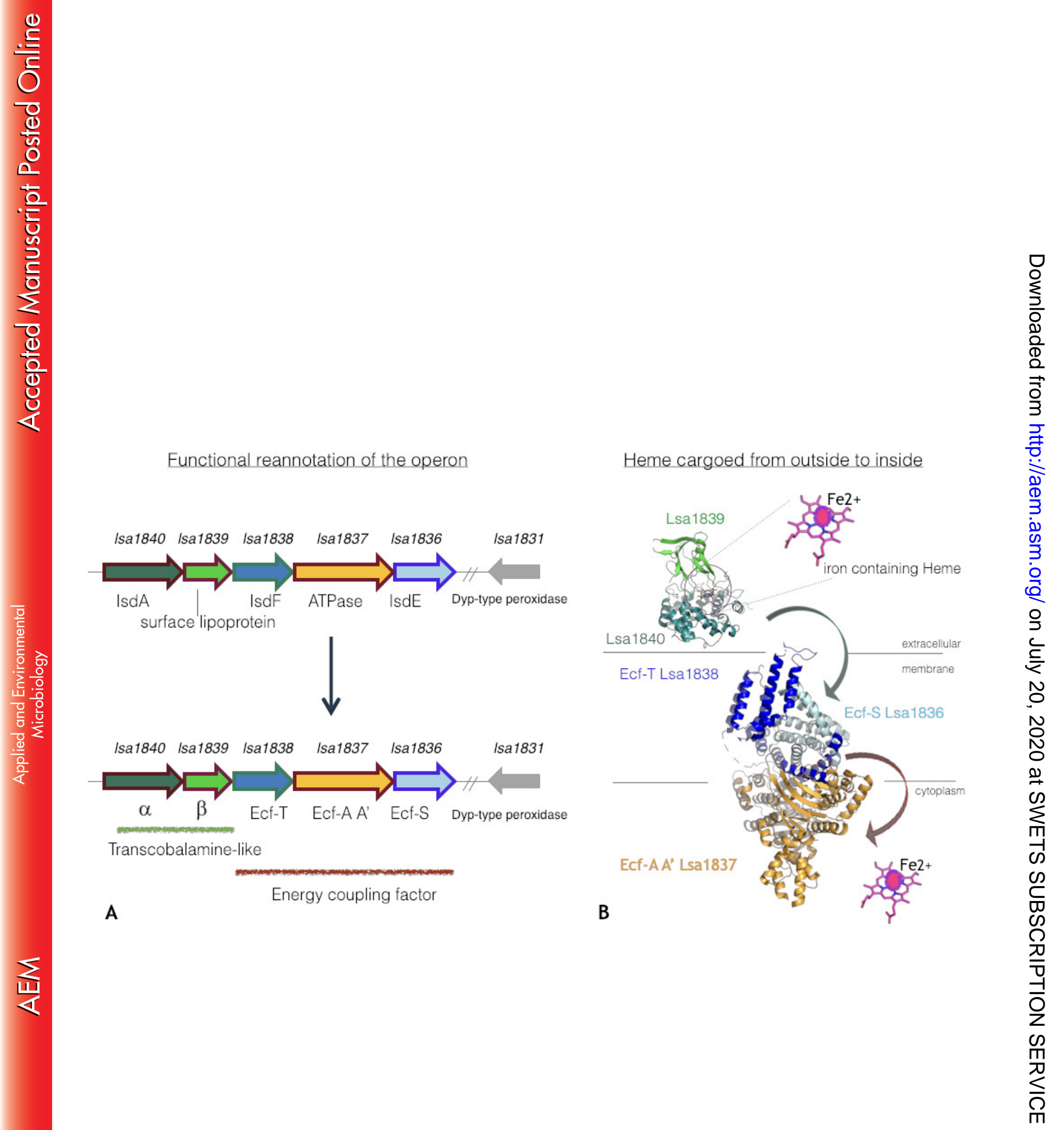

